\title{
INTERVENCIONES ENFERMERAS PARA \\ REDUCIR EL MIEDO AL PARTO. ESTUDIO \\ DE REVISIÓN BIBLIOGRÁFICA ${ }^{1}$
}

\section{Nursing Interventions to Reduce Fear of Childbirth: A Literature Review Study}

\author{
Marta Arranz Terensi ${ }^{1}$ \\ Correo electrónico: martaarranzterensi@gmail.com
}

1. Graduada en Enfermería. Universitat de Barcelona. (Barcelona, España)

Recibido: 28/05/2020 Aceptado: 02/12/2020

(c) (7) ()ㅜ

${ }^{1}$ Este artículo deriva del Trabajo fin de grado realizado en cuarto curso del grado de Enfermería (Facultad de Medicina y Ciencias de la Salud) de la Universitat de Barcelona por la autora y tutorizado por la Dra. Josefina Goberna Tricas durante el curso académico 2019/2020. 


\section{RESUMEN}

INTRODUCCIóN. El miedo al parto durante el embarazo tiene repercusiones en la vida diaria de la mujer y afecta a su bienestar. Las matronas, como profesionales de referencia en la atención del embarazo y parto normales, han de procurar restablecer la confianza de las mujeres en su cuerpo y garantizar que todas tengan acceso al soporte, cuidados e información que promuevan una experiencia de parto positiva. OBJETIVOS. Identificar las intervenciones enfermeras dirigidas a reducir el miedo al parto en mujeres embarazadas. METODOLOGía. Revisión bibliográfica en la que se han utilizado las bases de datos de PubMed, Cinahl, Cochrane Library, Scielo, Scopus, Cuidatge y Cuiden. Resultados. Se han incluido un total de 24 artículos: cuatro estudios observacionales, cuatro experimentales, cinco ensayos clínicos aleatorizados, dos cuasiexperimentales, tres cualitativos, cinco revisiones sistemáticas y uno de metodología mixta cualitativa/cuantitativa. Los resultados que se han obtenido hacen referencia a intervenciones como: asesoramiento (counselling), mindfulness, educación prenatal, uso del role play, la terapia con arte, la psico-educación y la preparación para el parto con acompañante (companion-integrated childbirth preparation). ConcLusIONES. Podemos afirmar que hay una gran variedad de intervenciones para el manejo del miedo al parto en mujeres embarazadas. Las intervenciones estudiadas han obtenido resultados positivos en la reducción del miedo al parto. El mejor modelo asistencial para reducir el miedo al parto se ha visto que es el de la continuidad asistencial. Por último, habría que aumentar el número de estudios en nuestro entorno geográfico y cultural.

Palabras clave: miedo; parto; matrona; intervenciones.

\section{ABSTRACT}

BACKGROUND. Fear of childbirth during pregnancy has an impact on a woman's daily life and affects her well-being. Midwives, as reference professionals in pregnancy and normal birth care, should seek to restore women's confidence in their bodies and ensure that they all have access to the support, care and information that promotes a positive birth experience. OBJECTIVES. Identify the nurse interventions aimed at reducing fear of childbirth in pregnant women. METHODOLOGY. In this bibliographic review we have used the databases PubMed, Cinahl, Cochrane Library, Scielo, Scopus, Cuidatge and Cuiden. RESULTS. There are included a total of 24 articles: four observational studies, four experimental studies, five randomized clinical trials, two quasi-experimental studies, three qualitative studies, five systematic reviews and one of mixed qualitative/quantitative methodology. The results obtained refer to interventions such as: counselling, mindfulness, antenatal education, the use of role play, art therapy, psychoeducation and companion-integrated childbirth preparation. CONCLUSION. We can say that there are a variety of interventions for managing childbirth fear in pregnant women. The interventions studied have shown positive results in reducing the fear of childbirth. The best healthcare model to reduce the fear of childbirth has been found to be the continuity of care. Lastly, the number of studies in our geographical and cultural environment should be increased.

Keywords. Fear; Childbirth; Midwife; Interventions. 


\section{INTRODUCCIÓN}

La Organización Mundial de la salud (OMS) recogió en la Declaración de Fortaleza las principales recomendaciones de lo que tenía que ser la atención a la maternidad en todo el mundo. En dicho documento se explica que toda mujer tiene derecho a una atención prenatal adecuada y a tener un papel central en todos los aspectos de esta atención, en los que se incluyen la participación, planificación, ejecución y evaluación de la atención. Hay que tener en cuenta que los factores sociales, emocionales y psicológicos son fundamentales para dar una atención perinatal adecuada (OMS, 2003).

El embarazo es un proceso natural de las mujeres en el que hay cambios físicos y psicológicos que necesitan de una adaptación (Cos, 2017). En el proceso de adaptación psicológica hay sentimientos de ambivalencia hacia el nuevo estado y posteriormente hay la aceptación del rol materno. Esta adaptación también genera sentimientos de estrés y ansiedad relacionados con el desarrollo del embarazo y el futuro parto que se expresan en forma de preocupación o miedo en aproximadamente un 80 \% de las mujeres embarazadas. No obstante, para algunas de estas mujeres el parto puede suponer una amenaza de daño y dolor que puede generar un miedo intenso (Ortega-Cejas et al., 2019).

El miedo al parto fue descrito por primera vez por el psiquiatra francés Louis Victor Marcé (1858). En el año 1981, en una población de mujeres embarazadas suecas, se definió el término «miedo al parto» como «una fuerte ansiedad que había deteriorado en las mujeres las actividades de la vida diaria y el bienestar». Un miedo más moderado se identificó como una ansiedad significativa, que no interfirió en la vida diaria de las mujeres (Nilsson et al., 2018). Más tarde, en un estudio hecho en Finlandia, Terhi Saisto y Erja Halmesmäki definieron el miedo al parto como un problema de salud para una gestante relacionado con un trastorno de ansiedad o una fobia en la que se incluían complicaciones físicas, pesadillas y problemas de concentración, así como demandas de cesárea (Saisto y Halmesmäki, 2003).

El término «miedo al parto clínico» describe un «miedo inhabilitante que interfiere en les actividades de la vida diaria y relaciones sociales» y, en algunos casos, hasta llega a la clasificación de una fobia específica según el DSM IV (Nilsson et al., 2018). Hofberg et al. (2003) introdujeron el término «tocofobia», definido como un miedo irracional al parto que puede inducir a la mujer a posponer o evitar el embarazo y/o a solicitar una cesárea electiva (Ortega-Cejas et al., 2019). 
La tocofobia puede ser primaria, que es la que suele aparecer en la adolescencia o edad adulta primeriza y en mujeres nulíparas. Por otra parte, se puede clasificar como tocofobia secundaria cuando aparece en mujeres que han tenido una experiencia previa de embarazo en el cual se han desarrollado miedos posteriormente o ha habido una experiencia traumática del parto, a veces relacionada con el trastorno de estrés postraumático (OrtegaCejas et al., 2019; Nilsson et al., 2018; Badaoui, Kassm y Naja, 2019). Además, el miedo al parto está fuertemente relacionado con el crecimiento del número de cesáreas, ya que habitualmente las mujeres que lo sufren tienden a evitar el parto vaginal y solicitan un parto quirúrgico (Nilsson et al., 2018). La prevalencia en el mundo de la tocofobia se considera que llega al 14 \% (Ead et al., 2017). En Europa la prevalencia parece variar entre países, oscilando entre el 1,9 y el $14 \%$ (Nilsson et al., 2018).

Henrietta Otley (2011) describe las causas del miedo al parto, analizándolas y dividiéndolas en las siguientes:

\section{Causas biológicas}

A pesar de que en las últimas décadas el empoderamiento de las mujeres en Occidente ha crecido, la confianza cultural y personal en su capacidad para dar a luz parece que ha disminuido, y esto ha ido acompañado de un aumento de los niveles de miedo al parto que a menudo las debilita. Las causas de este miedo son las historias negativas y el miedo al dolor en el trabajo de parto, que está asociado a sufrimiento, vergüenza, pérdida de control y falta de defensa. Sjögren (2000) encontró que las razones más habituales del miedo al parto eran la falta de confianza en el personal obstétrico y la sensación de exclusión de las decisiones. Esto nos ayuda a ver la importancia de una buena actuación de la matrona para mejorar la experiencia del embarazo y el parto de la mujer ofreciendo información, poder de decisión y defensa (Otley, 2011).

\section{Causas psicológicas}

Las investigaciones que han estudiado variables de personalidad sugieren que la depresión, la ansiedad y la baja autoestima están relacionadas de manera significativa con la tendencia de la mujer embarazada a temer el parto (Otley 2011; Demšar et al., 2018; Ortega-Cejas et al., 2019)

Lowe (2000) comprobó que las mujeres miedosas tenían una autoeficacia más baja, cosa que implica que tienen poca confianza en su capacidad de parir eficazmente, y este es 
un ámbito donde una buena matrona puede intervenir empoderando a las mujeres para que adquieran una mejor confianza en su cuerpo y proporcionando ayuda y soporte (Lowe 2000). Saisto y Halmesmäki recomiendan que las matronas estuvieran atentas a las mujeres que presentan quejas prenatales, como dolor abdominal recurrente, ya que esto podría enmascarar ansiedades sobre el parto (2003).

\section{Causas sociales}

Respecto a cuestiones sociales, la investigación de Henrietta Otley (2011) demuestra que las mujeres jóvenes que tienen un nivel educativo bajo y una red social pobre, o que manifiestan insatisfacción con sus parejas, son más propensas a verse afectadas por el miedo al parto. También tienen más riesgo de padecerlo las gestantes que han sufrido abuso sexual y que tienen un bajo nivel socioeconómico (Ortega-Cejas et al., 2019). Saber que estas mujeres son más vulnerables y tienen más riesgo de sufrir este miedo puede ayudar a las matronas a discernir qué mujeres necesitan una ayuda especial para construir su autoestima o para mejorar sus redes sociales, así como determinar en qué casos les iría bien la terapia psicológica.

\section{Causas culturales}

Las «historias de terror» sobre el parto han estado identificadas como una causa importante del miedo, especialmente en las mujeres primíparas y estas contribuyen a la concepción de la experiencia de parto como temible. La información alarmante que explican los amigos, la familia y los medios de comunicación sobre el parto es difusa. Las historias de los profesionales de la salud también tienen un fuerte poder explicativo para causar miedo. Puede ser que nuestro clima sociocultural disminuya la creencia de las mujeres en sí mismas y en su cuerpo. Además, las mujeres consideran que la tasa de intervención y las tasas operativas son pruebas de que el parto es peligroso y espantoso y que ha de ser gestionado médicamente. Como acompañantes del embarazo y parto normal, las matronas tienen que restablecer la confianza de las mujeres en su cuerpo y garantizar que todas tengan acceso al soporte, cuidados e información que promuevan una experiencia de parto positiva. (Otley, 2011)

Las consecuencias de este miedo pueden generar en la mujer inseguridad, frustración y falta de autoeficacia en su capacidad para dar a luz. Asimismo, también pueden dar lugar a insomnio y depresión, solicitudes de cesárea, tasas más altas de cesárea urgente, de 
analgesia epidural, complicaciones durante el parto y/o distocia de expulsivo e incremento de la duración del trabajo de parto, así como una experiencia de parto negativa que aumentará el riego de miedo en embarazos posteriores y también inestabilidad emocional postnatal con sensación de fracaso personal (Otley, 2011; Ortega-Cejas et al., 2019).

Ante la situación descrita, podemos preguntarnos cuáles son las intervenciones que pueden llevarse a cabo para reducir el miedo al parto. En este trabajo abordaremos como objetivo principal identificar las intervenciones enfermeras dirigidas a reducir el miedo al parto en mujeres embarazadas. Como objetivos específicos, nos plantearemos conocer cuál es el mejor modelo asistencial para reducir el miedo al parto en mujeres embarazadas, describir las intervenciones enfermeras realizadas durante el embarazo para reducir el miedo al parto y determinar su efectividad.

\section{METODOLOGÍA}

Revisión bibliográfica que quiere plasmar las evidencias científicas que hay sobre el tema planteado. Se han utilizado las siguientes bases de datos como fuente de información: PubMed, Cinahl, Cochrane Library, Scielo, Scopus, Cuidatge y Cuiden. Para seleccionar las palabras clave se utilizó tesauros Medical Subject Headings (MeSH) y luego el Descriptor en Ciencias de la Salud (DeCS) para traducir correctamente las palabras clave utilizadas para la búsqueda de información.

Estas palabras clave se especifican en la tabla 1, y están clasificadas por idiomas:

Tabla 1. Palabras clave utilizadas

\begin{tabular}{|l|l|l|}
\multicolumn{1}{c}{ Castellano } & \multicolumn{2}{c|}{ Catalán } \\
\hline Miedo & Por & Fear \\
\hline Parto & Part & Parturition, childbirth \\
\hline Matrona & Llevadora & Midwife \\
\hline Intervenciones & Intervencions & Interventions \\
\hline
\end{tabular}

Los criterios de inclusión para la selección de los artículos han sido los siguientes:

- Artículos que traten sobre las intervenciones enfermeras/matronas

- Artículos en castellano, catalán e inglés 
- Artículos completos

- Artículos publicados a partir de 2015

Los criterios de exclusión utilizados han sido los siguientes:

- Artículos que no sean de acceso gratuito

- Artículos que traten sobre menores de 18 años con miedo al parto

- Artículos sobre intervenciones realizadas a las parejas de las mujeres que tienen miedo al parto

- Artículos que traten sobre intervenciones farmacológicas.

Después de realizar la búsqueda en las bases de datos, se procedió a seleccionar los artículos que cumplían con los requisitos comentados anteriormente. Podemos observar la selección en la siguiente tabla:

Tabla 2. Artículos seleccionados

\begin{tabular}{|c|c|c|c|c|}
\hline Bases de datos & Resultados & $\begin{array}{l}\text { Seleccionados } \\
\text { por el título }\end{array}$ & $\begin{array}{l}\text { Seleccionados } \\
\text { por el resumen y } \\
\text { eliminado los } \\
\text { repetidos }\end{array}$ & $\begin{array}{c}\text { Artículos } \\
\text { seleccionados } \\
\text { finalmente } \\
\text { después una } \\
\text { lectura completa }\end{array}$ \\
\hline PubMed & 259 & 55 & 30 & 18 \\
\hline Cinahl & 431 & 15 & 7 & 4 \\
\hline $\begin{array}{l}\text { Cochrane } \\
\text { Library }\end{array}$ & 210 & 54 & 4 & 2 \\
\hline Scielo & 36 & 2 & 2 & 0 \\
\hline Scopus & 73 & 14 & 1 & 0 \\
\hline Cuidatge & 1 & 0 & 0 & 0 \\
\hline Cuiden & 127 & 1 & 0 & 0 \\
\hline
\end{tabular}




\section{RESULTADOS}

Se han seleccionado 24 artículos, el diseño metodológico se muestra en la tabla 3.

Tabla 3. Diseño metodológico de los artículos consultados

\begin{tabular}{ll}
\hline Estudio observacional & 4 \\
\hline Estudio experimental & 4 \\
\hline Ensayo clínico aleatorizado & 5 \\
\hline Estudio cuasiexperimental & 2 \\
\hline Revisión sistemática & 5 \\
Estudio cualitativo & 3 \\
Metodología mixta & 1 \\
cualitativa/cuantitativa & \\
\hline TOTAL & 24 \\
\hline
\end{tabular}

En la tabla 4 (ver página siguiente y siguientes), se muestran los principales resultados obtenidos de los artículos incluidos. 
Tabla 4. Síntesis de los resultados de la revisión bibliográfica

\begin{tabular}{|c|c|c|c|}
\hline $\begin{array}{c}\text { Título, Autor, Año, País, Tipo de } \\
\text { estudio }\end{array}$ & Objetivo & Métodos & Resultados y Conclusiones \\
\hline $\begin{array}{l}\text { A known midwife can make a difference } \\
\text { for women with fear of childbirth- birth } \\
\text { outcome and women's experiences of } \\
\text { intrapartum care } \\
\text { Ingegerd Hildingsson, Christine } \\
\text { Rubertsson, Annika Karlström, Helen } \\
\text { Haines } \\
\text { 2019. Suecia. Estudio experimental } \\
\text { (Hildingsson, Rubertsson, et al. 2019) }\end{array}$ & $\begin{array}{l}\text { Describir y comparar el } \\
\text { resultado del parto y la } \\
\text { experiencia de la atención } \\
\text { intraparto entre mujeres con } \\
\text { miedo al parto que han } \\
\text { recibido atención intraparto } \\
\text { de una matrona conocida } \\
\text { con aquellas que no. }\end{array}$ & $\begin{array}{l}70 \text { mujeres recibieron asesoramiento de } \\
\text { una matrona para el miedo al parto durante } \\
\text { el embarazo. } \\
\text { Cuando fue posible estas mujeres fueron } \\
\text { asistidas por la matrona conocida durante } \\
\text { el parto. }\end{array}$ & $\begin{array}{l}\text { Tener una matrona conocida durante el parto } \\
\text { tuvo } 5 \text { veces más probabilidades de tener una } \\
\text { experiencia de parto positiva. No hubo } \\
\text { diferencias respecto al inicio del parto ni al } \\
\text { tipo. } \\
\text { Las mujeres que tuvieron una matrona conocida } \\
\text { durante el parto tuvieron una mejor atención } \\
\text { respecto a la información, la participación en la } \\
\text { toma de decisiones y la percepción de control. }\end{array}$ \\
\hline $\begin{array}{c}\text { Título, Autor, Año, País, Tipo de } \\
\text { estudio }\end{array}$ & Objetivo & Métodos & Resultados y Conclusiones \\
\hline $\begin{array}{l}\text { A systematic review of } \\
\text { nonpharmacological prenatal } \\
\text { interventions for pregnancy-specific } \\
\text { anxiety and fear of childbirth } \\
\text { Kathrin Stoll, Emma Marie Swift, Nichole } \\
\text { Fairbrother, Elizabeth Nethery, Patricia } \\
\text { Janssen } \\
\text { 2018. Canadá. Revisión sistemática. } \\
\text { (Stoll et al. 2018) }\end{array}$ & $\begin{array}{l}\text { Resumir estudios de calidad } \\
\text { alta sobre intervenciones } \\
\text { prenatales no } \\
\text { farmacológicas que están } \\
\text { relacionadas con la } \\
\text { reducción de la ansiedad } \\
\text { específica del embarazo y el } \\
\text { miedo al parto. }\end{array}$ & $\begin{array}{l}\text { Se buscaron artículos en PubMed y } \\
\text { Mendeley con una combinación de } 42 \\
\text { términos de búsqueda. Dieciséis estudios } \\
\text { cumplieron los criterios de inclusión: una } \\
\text { intervención, un componente educativo o } \\
\text { un régimen de tratamiento para la ansiedad } \\
\text { específica del embarazo o el miedo al parto } \\
\text { durante el embarazo e incluyó un grupo } \\
\text { control. Finalmente, se escogieron siete } \\
\text { estudios. }\end{array}$ & $\begin{array}{l}\text { En cinco estudios se encontraron cambios } \\
\text { significativos en la ansiedad específica del } \\
\text { embarazo o en el miedo al parto, como } \\
\text { resultado de la intervención. Las intervenciones } \\
\text { psicoterapéuticas cortas individuales realizadas } \\
\text { por matronas fueron efectivas para mujeres con } \\
\text { miedo elevado al parto. Las intervenciones que } \\
\text { fueron efectivas fueron la educación del parto } \\
\text { en el hospital, el Hatha yoga prenatal y un } \\
\text { curso de educación prenatal. }\end{array}$ \\
\hline
\end{tabular}




\begin{tabular}{|c|c|c|c|}
\hline $\begin{array}{c}\text { Título, Autor, Año, País, Tipo de } \\
\text { estudio }\end{array}$ & Objetivo & Métodos & Resultados y Conclusiones \\
\hline $\begin{array}{l}\text { Caseload midwifery for women with fear } \\
\text { of birth is a feasible option } \\
\text { Ingegerd Hildingsson, Christine } \\
\text { Rubertsson, Annika Karlström, Helen } \\
\text { Haines } \\
\text { 2018. Suecia. Estudio de viabilidad } \\
\text { (Hildingsson et al. 2018) }\end{array}$ & $\begin{array}{l}\text { Poner a prueba un modelo } \\
\text { modificado de cuidados de } \\
\text { las matronas para } \\
\text { proporcionar continuidad } \\
\text { de estas a las mujeres con } \\
\text { miedo al parto y además } \\
\text { comprobar si esta } \\
\text { continuidad reducía el } \\
\text { miedo al parto. }\end{array}$ & $\begin{array}{l}\text { Se ofreció una visita extra en la semana } 25 \text { y } \\
\text { fueron invitadas a participar en el curso de } \\
\text { psicoprofilaxis. En las visitas las matronas se } \\
\text { centraron en hablar de sentimientos, las } \\
\text { causas del miedo y estrategias para hacerle } \\
\text { frente. Se procuró que las mujeres pudieran } \\
\text { ser atendidas por la misma matrona que les } \\
\text { había hecho las visitas. Los datos se } \\
\text { recogieron con cuestionarios a la mitad y final } \\
\text { del embarazo y dos meses después del parto. }\end{array}$ & $\begin{array}{l}\text { Ocho de las diez mujeres recibieron toda la } \\
\text { atención prenatal e intraparto de una matrona } \\
\text { conocida. La mayoría tuvieron un parto vaginal } \\
\text { normal con un alivio del dolor no } \\
\text { farmacológico. La satisfacción fue alta y la } \\
\text { mayoría de las mujeres dijeron que el miedo al } \\
\text { parto había disminuido o desaparecido. }\end{array}$ \\
\hline $\begin{array}{c}\text { Título, Autor, Año, País, Tipo de } \\
\text { estudio }\end{array}$ & Objetivo & Métodos & Resultados y Conclusiones \\
\hline $\begin{array}{l}\text { Effects of continuous midwifery labour } \\
\text { support for women with severe fear of } \\
\text { childbirth } \\
\text { Gunilla Sydsjö, Marie Blomberg, Sofie } \\
\text { Palmquist, Louise Angerbjörn, Marie } \\
\text { Bladh, Ann Josefsson } \\
\text { 2015. Suecia. Estudio piloto de casos y } \\
\text { control. } \\
\text { (Sydsjö et al. 2015) }\end{array}$ & $\begin{array}{l}\text { Evaluar como el soporte } \\
\text { continuo de una matrona } \\
\text { asignada durante el trabajo } \\
\text { de parto afecta al resultado } \\
\text { y a la experiencia subjetiva } \\
\text { en mujeres con miedo al } \\
\text { parto grave. }\end{array}$ & $\begin{array}{l}\text { Hay un grupo índice de } 14 \text { mujeres con miedo } \\
\text { al parto grave y un grupo control de } 28 \\
\text { mujeres sin miedo al parto. } \\
\text { El grupo índice recibió un soporte continuo } \\
\text { de una matrona durante el parto, quien era } \\
\text { consciente de la importancia que tiene el } \\
\text { soporte continuado para mejorar la } \\
\text { experiencia del parto en mujeres con miedo al } \\
\text { parto grave. }\end{array}$ & $\begin{array}{l}\text { Las mujeres con miedo al parto tenían más a } \\
\text { menudo una inducción al parto. Las mujeres del } \\
\text { grupo índice tuvieron una duración del parto } \\
\text { más corta que las del grupo control. No hubo } \\
\text { diferencia en la frecuencia de cesárea entre } \\
\text { grupos. Las mujeres con miedo al parto grave } \\
\text { experimentaron un nivel de ansiedad alto. Las } \\
\text { mujeres con miedo al parto pueden beneficiarse } \\
\text { de soporte continuo de una matrona en el parto. }\end{array}$ \\
\hline
\end{tabular}




\begin{tabular}{|c|c|c|c|}
\hline $\begin{array}{l}\text { Título, Autor, Año, País, Tipo de } \\
\text { estudio }\end{array}$ & Objetivo & Métodos & Resultados y Conclusiones \\
\hline $\begin{array}{l}\text { Women with fear of childbirth might } \\
\text { benefit from having a known midwife } \\
\text { during labour } \\
\text { Ingegerd Hildingsson, Annika } \\
\text { Karlström, Christine Rubertsson, } \\
\text { Helen Haines } \\
\text { 2019. Suecia. Estudio piloto } \\
\text { experimental. } \\
\text { (Hildingsson, Karlström, et al., 2019) }\end{array}$ & $\begin{array}{l}\text { Describir la prevalencia y los } \\
\text { factores relacionados con el } \\
\text { acceso a una matrona conocida } \\
\text { para las mujeres que reciben } \\
\text { asesoramiento para el miedo al } \\
\text { parto. } \\
\text { Explorar si el nivel de miedo } \\
\text { varía en las mujeres con el } \\
\text { paso del tiempo. }\end{array}$ & $\begin{array}{l}70 \text { mujeres con miedo al parto recibieron } \\
\text { asesoramiento y cuando era posible la } \\
\text { matrona que las había asesorado las asistía en } \\
\text { el momento del parto. }\end{array}$ & $\begin{array}{l}\text { El } 34 \text { \% de las mujeres tuvieron una matrona } \\
\text { conocida durante el parto. Estas tenían más } \\
\text { visitas de asesoramiento, consideraban } \\
\text { importante la continuidad existencial, estaban } \\
\text { más satisfechas con el asesoramiento y el } 29 \text { \% } \\
\text { declararon que el miedo desaparecía. } \\
\text { El temor al parto disminuyó significativamente } \\
\text { con el paso del tiempo en todas las mujeres, } \\
\text { independientemente que tuvieran o no una } \\
\text { matrona conocida. }\end{array}$ \\
\hline $\begin{array}{l}\text { Título, Autor, Año, País, Tipo de } \\
\text { estudio }\end{array}$ & Objetivo & Métodos & Resultados y Conclusiones \\
\hline $\begin{array}{l}\text { Counseling for childbirth fear - a } \\
\text { national survey } \\
\text { Birgitta Larsson, Annika Karlström, } \\
\text { Christine Rubertsson, Ingegerd } \\
\text { Hildingsson } \\
\text { 2016. Suecia. Estudio transversal. } \\
\text { (Larsson et al., 2016) }\end{array}$ & $\begin{array}{l}\text { Describir el contenido y } \\
\text { organización del } \\
\text { asesoramiento para el miedo al } \\
\text { parto dirigido por la matrona } \\
\text { en todas las clínicas obstétricas } \\
\text { de Suecia }\end{array}$ & $\begin{array}{l}\text { Se recogieron datos mediante un cuestionario } \\
\text { enviado a todas las clínicas obstétricas de } \\
\text { Suecia ( } \mathrm{n}=45 \text { ); un total de } 43 \text { clínicas } \\
\text { contestaron. En el análisis se utilizó un } \\
\text { ANOVA descriptivo y unidireccional. }\end{array}$ & $\begin{array}{l}\text { Todas las clínicas obstétricas ofrecen } \\
\text { asesoramiento dirigido por matronas a mujeres } \\
\text { con miedo al parto. Se observan diferencias en } \\
\text { el tiempo asignado al asesoramiento, con rango } \\
\text { entre } 5,7 \text { y 47,6 minutos. } \\
\text { La educación complementaria para las } \\
\text { matronas y la disponibilidad de opciones de } \\
\text { tratamiento variaban entre las diferentes } \\
\text { clínicas y no se relacionaban con la medida de } \\
\text { la clínica. }\end{array}$ \\
\hline
\end{tabular}




\begin{tabular}{|c|c|c|c|}
\hline $\begin{array}{c}\text { Título, Autor, Año, País, Tipo de } \\
\text { estudio }\end{array}$ & Objetivo & Métodos & Resultados y Conclusiones \\
\hline $\begin{array}{l}\text { Midwives' counselling of women at } \\
\text { specialised fear of childbirth clinics: } \\
\text { A qualitative study } \\
\text { Ann-Charlotte Wulcana, Christina } \\
\text { Nilsson } \\
\text { 2019. Suecia. Estudio cualitativo } \\
\text { (Wulcan y Nilsson 2019) }\end{array}$ & $\begin{array}{l}\text { Explorar y describir el } \\
\text { asesoramiento a mujeres con } \\
\text { miedo intenso al parto des del } \\
\text { punto de vista de las matronas } \\
\text { que lo proporcionan. }\end{array}$ & $\begin{array}{l}\text { Se hicieron entrevistas grupales a } 13 \text { matronas } \\
\text { y se hizo un análisis de su contenido. }\end{array}$ & $\begin{array}{l}\text { Varias matronas expresaron que les era difícil } \\
\text { describir una sesión de asesoramiento típica. } \\
\text { El asesoramiento a mujeres con miedo intenso } \\
\text { al parto se describe como «esforzarse para crear } \\
\text { un lugar seguro para explorar el miedo al } \\
\text { parto», que incluye las siguientes categorías: } \\
\text { proporcionar una relación de confianza; } \\
\text { investigar miedos anteriores y presentes; y una } \\
\text { fuerte dedicación a las mujeres. }\end{array}$ \\
\hline $\begin{array}{c}\text { Título, Autor, Año, País, Tipo de } \\
\text { estudio }\end{array}$ & Objetivo & Métodos & Resultados y Conclusiones \\
\hline $\begin{array}{l}\text { The effect of individual counselling } \\
\text { program by a midwife on fear of } \\
\text { childbirth in primiparous women } \\
\text { Nafise Andaroon, Masoumeh Kordi, } \\
\text { Seyed Ali Kimiaei, Habibollah } \\
\text { Esmaeily } \\
\text { 2018. Irán. Ensayo clínico } \\
\text { (Andaroon et al., 2018) }\end{array}$ & $\begin{array}{l}\text { Determinar el efecto del } \\
\text { programa de asesoramiento } \\
\text { individual de las matronas para } \\
\text { el miedo al parto de mujeres } \\
\text { primíparas. }\end{array}$ & $\begin{array}{l}90 \text { mujeres primíparas con edades } \\
\text { gestacionales de } 28-30 \text { semanas, que se } \\
\text { presentaron a los centros asistenciales de } \\
\text { Mashhad fueron reclutadas. } \\
\text { Las dividieron aleatoriamente en dos grupos: } \\
\text { intervención y control. El grupo de } \\
\text { intervención recibió el programa de } \\
\text { asesoramiento individual durante tres } \\
\text { sesiones y el grupo control atención rutinaria. }\end{array}$ & $\begin{array}{l}\text { Se encontró que el asesoramiento individual a } \\
\text { mujeres primíparas hecho por una matrona } \\
\text { durante el embarazo reduce el miedo al parto. }\end{array}$ \\
\hline
\end{tabular}




\begin{tabular}{|c|c|c|c|}
\hline Título, Autor, Año, País, Tipo de estudio & Objetivo & Métodos & Resultados y Conclusiones \\
\hline $\begin{array}{l}\text { The effects of counseling on fear of } \\
\text { childbirth } \\
\text { Birgitta Larsson, Annika Karlström, } \\
\text { Christine Rubertsson, Ingegerd Hildingsson } \\
\text { 2015. Suecia. Estudio longitudinal } \\
\text { (Larsson et al., 2015) }\end{array}$ & $\begin{array}{l}\text { Investigar las } \\
\text { experiencias de las } \\
\text { mujeres al asistir a } \\
\text { programas de } \\
\text { asesoramiento para el } \\
\text { miedo relacionado con } \\
\text { el parto y el efecto de } \\
\text { este asesoramiento a lo } \\
\text { largo del tiempo. }\end{array}$ & $\begin{array}{l}936 \text { mujeres fueron reclutadas. De estas, } 70 \text {, } \\
\text { grupo de intervención, recibieron } \\
\text { asesoramiento para el miedo al parto. Se } \\
\text { recogieron cuestionarios } 2 \text { meses y } 1 \text { año } \\
\text { después de haber parido y se recogieron datos } \\
\text { durante el embarazo. Se compararon las } \\
\text { mujeres que recibieron asesoramiento con las } \\
\text { que no. Se midió el miedo al parto, se } \\
\text { investigó la experiencia de parto y tipo de } \\
\text { parto que preferían. }\end{array}$ & $\begin{array}{l}\text { Las mujeres del grupo de asesoramiento un año } \\
\text { después del parto manifestaron más miedo al } \\
\text { parto, habían tenido una mala experiencia y en } \\
\text { caso de tener otro embarazo muchas preferían } \\
\text { una cesárea. Además, muchas habían dado a } \\
\text { luz por cesárea planificada. El } 80 \text { \% se } \\
\text { mostraron satisfechas con el soporte recibido. } \\
\text { Para ayudar a las mujeres con miedo al parto, } \\
\text { se necesitan métodos de tratamiento más } \\
\text { efectivos. }\end{array}$ \\
\hline Título, Autor, Año, País, Tipo de estudio & Objetivo & Métodos & Resultados y Conclusiones \\
\hline $\begin{array}{l}\text { Effects of extended childbirth education by } \\
\text { midwifes on the childbirth fear of first-time } \\
\text { mothers: an RCT } \\
\text { Sari Haapio, Marja Kaunonen, Martti } \\
\text { Arffman, Päivi Astedt-Kurki } \\
\text { 2017. Finlandia. Ensayo controlado } \\
\text { aleatorizado. } \\
\text { (Haapio et al., 2017) }\end{array}$ & $\begin{array}{l}\text { Explorar como afecta la } \\
\text { intervención de } \\
\text { educación en el parto } \\
\text { en mujeres primíparas } \\
\text { que tienen miedo al } \\
\text { parto y su } \\
\text { manifestación durante } \\
\text { el embarazo. }\end{array}$ & $\begin{array}{l}\text { Se reclutaron } 659 \text { mujeres primíparas antes de } \\
\text { la semana } 14 \text { de gestación durante la primera } \\
\text { ecografía. } \\
\text { Las mujeres fueron asignadas aleatoriamente } \\
338 \text { al grupo de intervención y } 321 \text { al grupo } \\
\text { control. } \\
\text { El grupo control recibió la educación para el } \\
\text { parto regular. El grupo de intervención } \\
\text { recibieron una educación para el parto de más } \\
\text { de dos horas. }\end{array}$ & $\begin{array}{l}\text { Las mujeres del grupo de intervención tuvieron } \\
\text { menos miedo al parto que las que estaban en el } \\
\text { grupo control. } \\
\text { Además, el miedo al parto afectó menos en la } \\
\text { vida diaria de las del grupo de intervención que } \\
\text { de las del grupo control. }\end{array}$ \\
\hline
\end{tabular}




\begin{tabular}{|c|c|c|c|}
\hline $\begin{array}{l}\text { Título, Autor, Año, País, Tipo de } \\
\text { estudio }\end{array}$ & Objetivo & Métodos & Resultados y Conclusiones \\
\hline $\begin{array}{l}\text { Women's experience of midwife-led } \\
\text { counselling and its influence on childbirth } \\
\text { fear: A qualitative study } \\
\text { Birgitta Larsson, Ingegerd Hildingsson, } \\
\text { Christine Rubertsson, Annika Karlström } \\
\text { 2019. Suecia. Estudio cualitativo de } \\
\text { entrevistas. (Larsson et al., 2019) }\end{array}$ & $\begin{array}{l}\text { Explorar las experiencias } \\
\text { de las mujeres en el } \\
\text { asesoramiento de las } \\
\text { matronas por el miedo al } \\
\text { parto. }\end{array}$ & $\begin{array}{l}\text { Se hicieron entrevistas por teléfono a } 27 \\
\text { mujeres } 2 \text { años después del parto las cuales } \\
\text { habían recibido asesoramiento durante el } \\
\text { embarazo. }\end{array}$ & $\begin{array}{l}\text { El asesoramiento dirigido por la matrona } \\
\text { comportó sentimientos positivos y se identificó } \\
\text { una mejor confianza en el parto. Las mujeres } \\
\text { experimentaban un mayor sentimiento de calma } \\
\text { que aumentó la tolerancia ante de la incerteza } \\
\text { relacionada con el proceso de paro. El miedo al } \\
\text { parto fue descrito como reducido o manejable. }\end{array}$ \\
\hline $\begin{array}{c}\text { Título, Autor, Año, País, Tipo de } \\
\text { estudio }\end{array}$ & Objetivo & Métodos & Resultados y Conclusiones \\
\hline $\begin{array}{l}\text { Gaining hope and self-confidence - An } \\
\text { interview study of women's experience of } \\
\text { treatment by art therapy for severe fear of } \\
\text { childbirth } \\
\text { Helén Wahlbeck, Linda J. Kvist, Kajsa } \\
\text { Landgren } \\
\text { 2018.Suecia. Estudio cualitativo } \\
\text { inductive. } \\
\text { (Wahlbeck, Kvist y Landgren, 2018) }\end{array}$ & $\begin{array}{l}\text { Describir la experiencia } \\
\text { de la terapia artística en } \\
\text { mujeres con miedo al } \\
\text { parto severo. }\end{array}$ & $\begin{array}{l}19 \text { mujeres con miedo severo al parto } \\
\text { recibieron soporte de un equipo de matronas } \\
\text { especialistas y tratamiento de una terapeuta } \\
\text { de arte que también era una matrona. } \\
\text { Tres meses después del parto fueron } \\
\text { entrevistadas sobre su experiencia con este } \\
\text { tratamiento. Después estas entrevistas fueron } \\
\text { analizadas. }\end{array}$ & $\begin{array}{l}\text { Después del análisis de las entrevistas el tema } \\
\text { principal que surgió fue ganar esperanza y } \\
\text { confianza en ellas mismas. Los otros fueron } \\
\text { llevar una mochila cargada, crear imágenes para } \\
\text { curarse y ganar nuevas visiones y habilidades. } \\
\text { Mediante las imágenes y colores, las mujeres } \\
\text { accedieron a emociones difíciles y el acto de } \\
\text { pintar las ayudó a visualizar estas emociones y } \\
\text { actuaron como ayuda en el proceso de curación. } \\
\text { La terapia artística fue bien aceptada por las } \\
\text { mujeres. }\end{array}$ \\
\hline
\end{tabular}




\begin{tabular}{|c|c|c|c|}
\hline $\begin{array}{c}\text { Título, Autor, Año, País, Tipo de } \\
\text { estudio }\end{array}$ & Objetivo & Métodos & Resultados y Conclusiones \\
\hline $\begin{array}{l}\text { Benefits of preparing for childbirth } \\
\text { with mindfulness training: a } \\
\text { randomized controlled trial with } \\
\text { active comparison } \\
\text { Larissa G. Duncan, Michael A. } \\
\text { Cohn, Maria T. Chao, Joseph G. } \\
\text { Cook, Jane Riccobono and Nancy } \\
\text { Bardacke } \\
\text { 2017. Estados Unidos. Ensayo } \\
\text { controlado aleatorizado. } \\
\text { (Duncan et al. 2017) }\end{array}$ & $\begin{array}{l}\text { Comparar el mindfulness } \\
\text { llevado a cabo con el «Mind in } \\
\text { Labor (MIL): Working with } \\
\text { Pain in Childbirth»y la } \\
\text { educación estándar para el } \\
\text { parto. }\end{array}$ & $\begin{array}{l}\text { Las mujeres primíparas a finales del tercer } \\
\text { trimestre de embarazo fueron asignadas al } \\
\text { azar para asistir al curso MIL o al curso } \\
\text { estándar de preparación para el parto. } \\
\text { Las participantes completaron evaluaciones } \\
\text { antes de la intervención, después de esta y } \\
\text { después del parto. También se recogieron } \\
\text { datos médicos. }\end{array}$ & $\begin{array}{l}\text { Se demuestra que el mindfulness mejoró la } \\
\text { evaluación del parto y funcionamiento } \\
\text { psicológico de las mujeres en comparación con } \\
\text { la educación estándar del parto. } \\
\text { Las participantes del programa MIL mostraron } \\
\text { una mayor autoeficacia del parto y conciencia } \\
\text { corporal. } \\
\text { Se mantuvieron menos síntomas de depresión } \\
\text { durante el seguimiento postparto. Hubo una } \\
\text { tendencia más baja a la utilización de analgesia } \\
\text { con opioides en el trabajo de parto. Aunque no } \\
\text { refirieron después del parto haber tenido menos } \\
\text { dolor ni utilizaron menos la epidural que el } \\
\text { grupo control. En conclusión, la atención para } \\
\text { abordar el miedo y el dolor del parto puede } \\
\text { traer beneficios para la salud mental materna, } \\
\text { como una mejora en la evaluación del parto y } \\
\text { prevención de los síntomas de depresión } \\
\text { postparto. }\end{array}$ \\
\hline
\end{tabular}




\begin{tabular}{|c|c|c|c|}
\hline $\begin{array}{l}\text { Título, Autor, Año, País, Tipo de } \\
\text { estudio }\end{array}$ & Objetivo & Métodos & Resultados y Conclusiones \\
\hline $\begin{array}{l}\text { Exploring the Effect of Mindfulness- } \\
\text { Based Stress Reduction on } \\
\text { Childbirth Fear Among Single-Child } \\
\text { Mothers in the City of Kerman, Iran } \\
\text { (2017): A Clinical Trial Study } \\
\text { Malihe Pour-Edalati, Nousirvan } \\
\text { Khezri Moghadam, Armita } \\
\text { Shahesmaeili, Parvin Salehi-Nejad } \\
\text { 2019. Irán. Ensayo clínico. } \\
\text { (Pour-Edalati et al., 2019) }\end{array}$ & $\begin{array}{l}\text { Investigar el impacto del } \\
\text { mindfulness basado en la } \\
\text { reducción del estrés (MBSR) } \\
\text { en el miedo al parto en mujeres } \\
\text { con un sol hijo y parto vaginal } \\
\text { anterior. }\end{array}$ & $\begin{array}{l}\text { La muestra fue de } 41 \text { mujeres, } 20 \text { recibieron } \\
\text { la formación del grupo MBSR en ocho } \\
\text { sesiones (cada una de } 90 \text { minutos) y las otras } \\
\text { fueron el grupo control. } \\
\text { El miedo al parto se evaluó antes y después } \\
\text { de la intervención mediante un cuestionario. } \\
\text { Los datos después fueron analizados. }\end{array}$ & $\begin{array}{l}\text { Antes de la intervención el miedo al parto era } \\
\text { más alta en el grupo de la intervención que en } \\
\text { el control. Después de la intervención el miedo } \\
\text { se redujo en el grupo de la intervención, } \\
\text { entonces se igualó al del grupo control. } \\
\text { Comparando la reducción del miedo en cada } \\
\text { grupo se vio que este era mucho mayor en el } \\
\text { grupo de la intervención. } \\
\text { Además, se observaron los mayores efectos de } \\
\text { las intervenciones en el miedo a las inyecciones } \\
\text { dolorosas, la solitud y la preocupación por el } \\
\text { entorno hospitalario. } \\
\text { La formación en grupo de MBSR es útil para } \\
\text { reducir el miedo al parto y, por eso, se puede } \\
\text { implementar como procedimiento para } \\
\text { fomentar el parto en mujeres que no quieren } \\
\text { quedarse embarazados por ese miedo. }\end{array}$ \\
\hline
\end{tabular}




\begin{tabular}{|c|c|c|c|}
\hline $\begin{array}{l}\text { Título, Autor, Año, País, Tipo de } \\
\text { estudio }\end{array}$ & Objetivo & Métodos & Resultados y Conclusiones \\
\hline $\begin{array}{l}\text { Does antenatal education reduce } \\
\text { fear of childbirth? } \\
\text { Karabulut Ö, Coşkuner Potur D, } \\
\text { Doğan Merih Y, Cebeci Mutlu S, } \\
\text { Demirci N } \\
\text { 2016. Turquía. Estudio } \\
\text { cuasiexperimental y prospectivo. } \\
\text { (Karabulut et al., 2016) }\end{array}$ & $\begin{array}{l}\text { Determinar el efecto de la } \\
\text { educación prenatal en el miedo } \\
\text { al parto, la aceptación del } \\
\text { embarazo y la identificación } \\
\text { del rol materno. }\end{array}$ & $\begin{array}{l}192 \text { dones embarazadas. El grupo educativo } \\
\text { (GE) estaba formado por } 69 \text { mujeres } \\
\text { embarazadas que se inscribieron } \\
\text { voluntariamente en el programa. El grupo } \\
\text { control (GC) consistía en } 123 \text { mujeres } \\
\text { embarazadas que no escogieron recibir } \\
\text { educación prenatal, pero que se ofrecieron } \\
\text { voluntarias para participar en el estudio. } \\
\text { En el GE las sesiones se realizaron una vez al } \\
\text { día, durante } 180 \text { minutos. Las mujeres } \\
\text { embarazadas y sus parejas, o algún familiar, } \\
\text { asistieron a las } 5 \text { sesiones predeterminadas. El } \\
\text { número mediano de participantes de cada } \\
\text { grupo fue de } 6 \text { a } 10 \text { parejas. La primera sesión } \\
\text { trataba sobre la salud en el embarazo, la } \\
\text { segunda sobre el parto y ejercicios de } \\
\text { respiración, la tercera sobre la lactancia } \\
\text { materna, la cuarta sobre los cuidados al recién } \\
\text { nacido y la última sobre el postparto y la } \\
\text { planificación familiar. El GC recibió solo } \\
\text { atención e información de rutina sobre el } \\
\text { embarazo. }\end{array}$ & $\begin{array}{l}\text { Después de participar en las sesiones } \\
\text { educativas se encontraron diferencias entre el } \\
\text { grupo control y el grupo educativo. } \\
\text { En este último grupo al finalizar las sesiones } \\
\text { había augmentado la aceptación del embarazo, } \\
\text { no había habido afectación en la identificación } \\
\text { del papel de la maternidad y había habido una } \\
\text { reducción del miedo al parto. } \\
\text { La educación prenatal augmenta la aceptación } \\
\text { del embarazo, no afecta a la identificación del } \\
\text { rol materno y reduce el miedo al parto. }\end{array}$ \\
\hline
\end{tabular}




\begin{tabular}{|c|c|c|c|}
\hline $\begin{array}{l}\text { Título, Autor, Año, País, Tipo de } \\
\text { estudio }\end{array}$ & Objetivo & Métodos & Resultados y Conclusiones \\
\hline $\begin{array}{l}\text { The effect of education given to } \\
\text { primigravida women on fear of } \\
\text { childbirth } \\
\text { Aynur Kızılırmak, Mürüvvet Başer } \\
\text { 2016. Turquía. Estudio experimental } \\
\text { con pre-post test y un grupo control. } \\
\text { (Kizilirmak y Başer, 2016) }\end{array}$ & $\begin{array}{l}\text { Determinar el efecto } \\
\text { de la educación para } \\
\text { mujeres primíparas } \\
\text { con miedo al parto. }\end{array}$ & $\begin{array}{l}99 \text { mujeres primíparas fueron reclutadas, } 50 \text { en el grupo de } \\
\text { estudio y } 49 \text { en el grupo control. La educación preparatoria } \\
\text { se proporcionó en dos sesiones entre las semanas } 28 \text { y } 34 \\
\text { de embarazo a las mujeres del grupo de intervención. Los } \\
\text { principales temas de la formación educativa fueron las } \\
\text { características y prácticas rutinarias en la sala de parto e } \\
\text { información sobre el parto. }\end{array}$ & $\begin{array}{l}\text { No se encontró diferencia significativa entre las } \\
\text { puntuaciones de los grupos de intervención y } \\
\text { control. La puntuación mediana «The Wijma } \\
\text { Delivery Expectancy/Experience Questionnaire } \\
\text { Version A» (W-DEQ-A) fue de 61,1 y de 42,0 } \\
\text { en el grupo de intervención. La puntuación W- } \\
\text { DEQ-A posteducativa fue de 58,5 en el grupo } \\
\text { control y 42,0 en el de intervención. La } \\
\text { educación proporcionó percepción positiva. }\end{array}$ \\
\hline $\begin{array}{l}\text { Título, Autor, Año, País, Tipo de } \\
\text { estudio }\end{array}$ & Objetivo & Métodos & Resultados y Conclusiones \\
\hline
\end{tabular}




\begin{tabular}{|c|c|c|c|}
\hline $\begin{array}{c}\text { Título, Autor, Año, País, Tipo de } \\
\text { estudio }\end{array}$ & Objetivo & Métodos & Resultados y Conclusiones \\
\hline $\begin{array}{l}\text { Effect of role play education on } \\
\text { primiparous women's fear of natural } \\
\text { delivery and their decision on the mode of } \\
\text { delivery } \\
\text { Maryam Navaee, Zahra Abedian } \\
\text { 2015. Irán. Ensayo clínico a ciegas. } \\
\text { (Navaee y Abedian, 2015) }\end{array}$ & $\begin{array}{l}\text { Describir el efecto de la } \\
\text { educación con roleplay en } \\
\text { mujeres primíparas que } \\
\text { tienen miedo al parto y su } \\
\text { decisión de tipo de parto. }\end{array}$ & $\begin{array}{l}67 \text { dones primíparas entre las 34-36 semanas } \\
\text { de gestación fueron aleatorizados en dos } \\
\text { grupos ( } 35 \text { en el grupo de role play y } 32 \text { en el } \\
\text { grupo de conferencia). Se investigó su miedo } \\
\text { al parto. } \\
\text { En uno de los grupos se hizo educación con } \\
\text { role play en tres escenarios durante siete } \\
\text { etapas. En el otro se hizo una sesión de } 90 \\
\text { minutos con PowerPoint. }\end{array}$ & $\begin{array}{l}\text { Después de la intervención hubo una diferencia } \\
\text { significativa en cuanto al miedo al parto en los } \\
\text { dos grupos, hubo una reducción de este en el } \\
\text { grupo de role play. Además, también hubo una } \\
\text { disminución de las elecciones de cesárea y la } \\
\text { decisión de tipo de parto en el momento de } \\
\text { entrar en la sala de partos. } \\
\text { Un } 75 \% \text { del grupo de conferencia y un } 100 \% \\
\text { del grupo de role play escogieron parto natural. }\end{array}$ \\
\hline $\begin{array}{c}\text { Título, Autor, Año, País, Tipo de } \\
\text { estudio }\end{array}$ & Objetivo & Métodos & Resultados y Conclusiones \\
\hline $\begin{array}{l}\text { Efficacy of companion-integrated } \\
\text { childbirth preparation for childbirth fear, } \\
\text { self-efficacy, and maternal support in } \\
\text { primigravid women in Malawi } \\
\text { Berlington M. J. Munkhondya, Tiwonge } \\
\text { Ethel Munkhondya, Ellen Chirwa, and } \\
\text { Honghong Wang } \\
\text { 2020. Malawi. Estudio cuasiexperimental. } \\
\text { (Munkhondya et al., 2020) }\end{array}$ & $\begin{array}{l}\text { Evaluar la eficacia de la } \\
\text { preparación para el parto } \\
\text { companion-integrated } \\
\text { durante el final del } \\
\text { embarazo para reducir el } \\
\text { miedo al parto, mejorar la } \\
\text { autoeficacia, el soporte en } \\
\text { las mujeres primíparas. }\end{array}$ & $\begin{array}{l}\text { Se reclutaron } 70 \text { mujeres, } 35 \text { en el grupo de } \\
\text { intervención y } 35 \text { en el grupo control. } \\
\text { En el grupo de intervención las mujeres } \\
\text { primíparas y su acompañante de parto } \\
\text { recibieron dos sesiones de preparación para el } \\
\text { parto companion-integrated. El grupo control } \\
\text { tubo unos cuidados rutinarios. } \\
\text { Se utilizaron varios cuestionarios para recoger } \\
\text { datos y estos fueron analizados. }\end{array}$ & $\begin{array}{l}\text { Antes de la intervención los resultados eran } \\
\text { similares en los dos grupos. } \\
\text { Después, en el grupo de intervención hubo una } \\
\text { reducción significativa del miedo al parto y una } \\
\text { mejora de la autoeficacia. Además, en el grupo } \\
\text { de intervención aumentó el soporte de los } \\
\text { acompañantes de parto. } \\
\text { No se encontraron diferencias en los resultados } \\
\text { del embarazo. }\end{array}$ \\
\hline
\end{tabular}




\begin{tabular}{|c|c|c|c|}
\hline Título, Autor, Año, País, Tipo de estudio & Objetivo & Métodos & Resultados y Conclusiones \\
\hline $\begin{array}{l}\text { Support for pregnant women identified with } \\
\text { fear of childbirth (FOC)/tokophobia - A } \\
\text { systematic review of approaches and } \\
\text { interventions } \\
\text { Sabine Striebich, Elke Mattern, Gertrud M. } \\
\text { Ayerle } \\
\text { 2018. Alemania. Revisión sistemática. } \\
\text { (Striebich, Mattern y Ayerle, 2018) }\end{array}$ & $\begin{array}{l}\text { Identificar y revisar } \\
\text { sistemáticamente los } \\
\text { estudios que examinan } \\
\text { las intervenciones para } \\
\text { aliviar el miedo severo } \\
\text { al parto en el embarazo } \\
\text { y en lo que se } \\
\text { fundamentan. }\end{array}$ & $\begin{array}{l}\text { Se realizó una búsqueda sistemática de } \\
\text { literatura. Los criterios de inclusión fueron: } \\
\text { estudios con mujeres embarazadas } \\
\text { diagnosticadas de miedo al parto alto o grave } \\
\text { o que solicitaban una cesárea, estudios } \\
\text { (independientemente del diseño) que } \\
\text { observaran el efecto de una intervención } \\
\text { dirigida al miedo al parto y estudios } \\
\text { publicados en inglés. Se excluyeron las } \\
\text { publicaciones sobre la ansiedad o el estrés. } \\
\text { Se seleccionaron } 377 \text { referencias. }\end{array}$ & $\begin{array}{l}\text { Se incluyeron } 19 \text { artículos en el análisis. Los } \\
\text { estudios muestran heterogeneidad en cuanto a } \\
\text { métodos de evaluación, tipos, } \\
\text { conceptualización y aplicación de } \\
\text { intervenciones. Tanto las sesiones de terapia } \\
\text { cognitiva como la psicoeducación en grupos } \\
\text { con relajación son intervenciones eficaces. Las } \\
\text { sesiones de psicoeducación o las } \\
\text { conversaciones terapéuticas tienen el potencial } \\
\text { de reforzar la autoeficacia de las mujeres y } \\
\text { disminuir el número de cesáreas. }\end{array}$ \\
\hline Título, Autor, Año, País, Tipo de estudio & Objetivo & Métodos & Resultados y Conclusiones \\
\hline $\begin{array}{l}\text { Antenatal and intrapartum interventions for } \\
\text { reducing caesarean section, promoting } \\
\text { vaginal birth, and reducing fear of childbirth: } \\
\text { An overview of systematic reviews } \\
\text { Valerie SmithID, Louise Gallagher, Margaret } \\
\text { Carroll, Kathleen Hannon, Cecily Begley } \\
\text { 2019. Irlanda. Revisión sistemática de } \\
\text { revisiones sistemáticas. } \\
\text { (Smith et al., 2019) }\end{array}$ & $\begin{array}{l}\text { Identificar las } \\
\text { intervenciones } \\
\text { prenatales e intraparto } \\
\text { que han demostrado ser } \\
\text { eficaces para reducir la } \\
\text { cesárea, promover el } \\
\text { parto vaginal y reducir } \\
\text { el miedo al parto. }\end{array}$ & $\begin{array}{l}\text { Se buscaron artículos en varias bases de } \\
\text { datos como Cochrane, PubMed, CINAHL, } \\
\text { EMBASE, etc. Se excluyeron las revisiones } \\
\text { valoradas como «críticamente bajas» en } \\
\text { AMSTAR-2. Se incluyeron } 101 \text { revisiones } \\
\text { sistemáticas y } 10 \text { informes de } \\
\text { recomendaciones basadas en la evidencia. }\end{array}$ & $\begin{array}{l}\text { Los resultados destacan que en } 17 \text { revisiones se } \\
\text { redujo el riesgo de cesárea. En } 9 \text { intervenciones } \\
\text { se aumentó el riesgo de cesárea. En } 8 \\
\text { intervenciones se redujo el parto vaginal } \\
\text { instrumental, en } 4 \text { aumentó el parto vaginal } \\
\text { espontaneo y en } 2 \text { se redujo el miedo al parto. }\end{array}$ \\
\hline
\end{tabular}




\begin{tabular}{|c|c|c|c|}
\hline $\begin{array}{l}\text { Título, Autor, Año, País, Tipo de } \\
\text { estudio }\end{array}$ & Objetivo & Métodos & Resultados y Conclusiones \\
\hline $\begin{array}{l}\text { Interventions for reducing fear of } \\
\text { childbirth: a systematic review and } \\
\text { meta-analysis of clinical trials } \\
\text { Vahideh Moghaddam Hosseinia, } \\
\text { Milad Nazarzadehb, Shayesteh } \\
\text { Jahanfar } \\
\text { 2018. Australia. Revisión sistemática } \\
\text { y metaanálisis de ensayos clínicos } \\
\text { (Moghaddam Hosseini, Nazarzadeh } \\
\text { y Jahanfar, 2018) }\end{array}$ & $\begin{array}{l}\text { Identificar las intervenciones } \\
\text { efectivas para reducir el miedo } \\
\text { al parto. }\end{array}$ & $\begin{array}{l}\text { Se buscaron artículos en varias bases de } \\
\text { datos. Se incluyeron ensayos controlados } \\
\text { aleatorizados y ensayos controlados cuasi } \\
\text { aleatorizados que comparaban intervenciones } \\
\text { para el tratamiento del miedo al parto. }\end{array}$ & $\begin{array}{l}\text { Se incluyeron diez estudios de } 3984 \\
\text { participantes. Dos estudios investigaron la } \\
\text { intervención basada en la hipnosis y ocho en la } \\
\text { educación. } \\
\text { Los dos tipos de intervenciones fueron } \\
\text { efectivas para reducir el miedo al parto; aún y } \\
\text { así, comparando los resultados se vio que las } \\
\text { intervenciones educativas reducían el miedo } \\
\text { con el doble de efecto que la hipnosis. }\end{array}$ \\
\hline $\begin{array}{c}\text { Título, Autor, Año, País, Tipo de } \\
\text { estudio }\end{array}$ & Objetivo & Métodos & Resultados y Conclusiones \\
\hline $\begin{array}{l}\text { Interventions for fear of childbirth } \\
\text { (tocophobia) } \\
\text { O’Connell MA, O’Neill SM, } \\
\text { Dempsey E, Khashan AS, Leahy- } \\
\text { Warren P, Smyth RMD, Kenny LC } \\
\text { 2019. Reino Unido. Revisión } \\
\text { sistemática. } \\
\text { (O’connell et al., 2019) }\end{array}$ & $\begin{array}{l}\text { Descubrir la efectividad de } \\
\text { intervenciones no } \\
\text { farmacológicas para reducir el } \\
\text { miedo al parto comparadas con } \\
\text { los cuidados estándares para } \\
\text { las mujeres con miedo al parto. }\end{array}$ & $\begin{array}{l}\text { Se recogerá todos los ensayos controlados } \\
\text { aleatorizados publicados sobre las } \\
\text { intervenciones farmacológicas en que el } \\
\text { objetivo primario o secundario sea tratar el } \\
\text { miedo al parto. }\end{array}$ & $\begin{array}{l}\text { Debido a que se trata de un protocolo de } \\
\text { investigación de investigación para una } \\
\text { revisión bibliográfica, el análisis no se ha } \\
\text { realizado aún, con lo cual, no se exponen } \\
\text { resultados ni conclusiones de la investigación. }\end{array}$ \\
\hline
\end{tabular}




\section{DISCUSIÓN}

Esta revisión bibliográfica tiene como objetivo principal conocer las intervenciones enfermeras que reducen el miedo al parto, describiendo y determinando su efectividad. Además, también quiere identificar cuál es el mejor modelo asistencial para reducirlo. En todos los estudios se considera muy importante la reducción de este miedo para el proceso de parto. La discusión se ha dividido en diferentes apartados de acuerdo con los objetivos planteados.

\section{Continuidad asistencial con la misma matrona}

Según cuatro estudios hechos en Suecia se encontró que el modelo asistencial basado en una continuidad asistencial generaba confianza en la matrona y reducía el miedo al parto de las mujeres estudiadas (Sydsjö et al., 2015; Hildingsson et al., 2018; Hildingsson, Karlström, et al., 2019; Hildingsson, Rubertsson, et al., 2019)

En un estudio experimental, hecho por Hildingsson et al., las mujeres que tenían una matrona conocida durante el parto tenían cinco veces más probabilidades de tener una experiencia de parto positiva. También había una mejor percepción del dolor. Además, sintieron un mayor control, estaban más informadas e involucradas en la toma de decisiones. No se encontraron diferencias en el tiempo, tipo de parto o en el uso de aliviadores del dolor, como la epidural, o en la frecuencia de cesáreas de emergencia y partos instrumentados (Hildingsson, Rubertsson, et al., 2019). Igualmente, en un estudio hecho por Sydsjö et al., tampoco se encontraron diferencias en estos ámbitos, en mujeres primíparas. Sin embargo, en mujeres multíparas que habían tenido continuidad asistencial sí que se vio que la duración del parto había sido más corta. También hubo una prevalencia más alta del uso de epidural en el grupo de intervención, que es normal, ya que el miedo al dolor es más frecuente en las mujeres con miedo al parto y este tiene que ser aliviado para que el parto vaginal vaya bien. En este estudio se afirmó que para las mujeres con miedo al parto es beneficioso tener el soporte de una matrona conocida durante el parto (Sydsjö et al., 2015).

Según Hildingsson et al., se puede afirmar que las mujeres que son cuidadas por varias matronas están menos satisfechas con los cuidados independientemente de si tienen o no miedo al parto (Hildingsson, Rubertsson, et al., 2019). En un estudio de viabilidad hecho por los mismos autores que el experimental, Hildingsson et al., muchas mujeres se 
mostraron satisfechas con la continuidad asistencial y lo preferían en caso de un próximo embarazo. En este estudio hubo diferencias entre los niveles de la escala FOBS (Fear of Birth Scale) y la autoevaluación que hacía la mujer sobre el efecto del asesoramiento. La mayoría de las mujeres dijeron que habían sentido una mejora en sus niveles de miedo y dos expresaron que el miedo había desaparecido. Pero, lo que se vio es que en tres casos los niveles de FOBS habían aumentado. También una mujer dijo que el asesoramiento no había afectado en su miedo, aunque se encontró que los niveles de FOBS habían disminuido durante su embarazo (Hildingsson et al., 2018). En el estudio de Sydsjö et al., las mujeres con miedo al parto dijeron que recomendarían a una amiga tener una matrona conocida durante el parto (Sydsjö et al., 2015). En un estudio piloto experimental, hecho también por Hildingsson et al., las mujeres que tuvieron una matrona conocida durante el parto dijeron que esta continuidad había sido «muy importante» o «importante» durante el embarazo. También se mostraban más satisfechas con el asesoramiento recibido (Hildingsson, Karlström, et al., 2019) . En dos de los estudios hechos por Hildingsson et al., se dice que la continuidad construirá una relación con la matrona que dará confianza y esta podrá escuchar y actuar según los deseos de la mujer y le podrá ofrecer un trato individualizado (Hildingsson, Karlström, et al., 2019; Hildingsson, Rubertsson, et al., 2019).

\section{Tipos de intervenciones}

\section{Asesoramiento (counselling)}

Hay cinco estudios en los que se hace énfasis en el asesoramiento (counselling) que se utiliza con el objetivo de reducir el miedo al parto. Cuatro de ellos se hicieron en Suecia y uno e Irán (Larsson et al., 2019; Wulcan y Nilsson, 2019; Andaroon et al., 2018; Larsson et al., 2015; 2016). Entre los estudios hay similitudes y discrepancias en lo que considera cada uno que es el asesoramiento (counselling).

El tiempo que se invierte en este es diferente. En un estudio transversal hecho por Larsson et al. se encontró que el tiempo destinado al asesoramiento variaba entre 5,7 y 47,6 minutos por mujer entre las clínicas analizadas (Larsson et al., 2016). En cambio, en un ensayo clínico hecho por Andaroon et al., en Irán, las sesiones fueron tres de 45-60 minutos cada dos semanas (Andaroon et al. 2018).

Las 43 clínicas analizadas en el estudio transversal hecho por Larsson et al. tenían matronas con experiencia en cuidados obstétricos para hacer el asesoramiento para tratar 
el miedo al parto. En 26 clínicas se incluían otros profesionales a parte de las matronas como los trabajadores sociales y los psicólogos (Larsson et al., 2016). Por otro lado, en un estudio longitudinal hecho por las mismas autoras que el estudio transversal, Larsson et al., también se incluían los obstetras (Larsson et al. 2015). En los cinco estudios en el contenido del asesoramiento se incluía dar información sobre el proceso de parto y mantener un diálogo fortalecedor con la mujer que contribuiría a augmentar la confianza de esta en ella misma y haría que se sintiera cómoda para explicar sus miedos (Wulcan y Nilsson, 2019; Andaroon et al., 2018; Larsson et al., 2019; 2016; 2015) .En un estudio cualitativo de entrevistas hecho por Larsson et al. también se visitaba la sala de partos y en el estudio transversal también se hacía en el 98 \% de las clínicas (Larsson et al. 2019; 2016).

En el estudio transversal hecho por Larsson et al. se ofrecía un alivio precoz del dolor, se informaba sobre los pros y contras del parto vaginal y la cesárea, se proponía un plan de parto, se revisaba el historial de parto y se hablaba sobre un parto pasado. En el 67 \% de las clínicas se enseñaban a las mujeres técnicas de relajación y respiración (Larsson et al., 2016). En el estudio cualitativo citado también se hablaba sobre un parto pasado con las mujeres que hubieran tenido una mala experiencia en un parto previo. (Larsson et al., 2019). En el ensayo clínico hecho por Andaroon et al., se les preguntaba sobre el tipo de parto que querían, se las ayudaba en su decisión y esta era apoyada. (Andaroon et al. 2018). Por otro lado, en un estudio cualitativo hecho por Wulcana y Nilsson incluso varias matronas dijeron que era difícil describir una sesión de asesoramiento típica, explicaron que el tema principal en el que se centraban las sesiones era: «Esforzarse por crear un lugar seguro para explorar el miedo al parto». (Wulcan y Nilsson, 2019)

En cuanto a la efectividad de esta intervención Andaroon et al., demostraron que el asesoramiento individual hecho por una matrona es efectivo en la reducción del miedo al parto, ya que el miedo en mujeres primíparas del grupo de intervención en la semana 3436 de gestación era significativamente más baja en el grupo de intervención, en concreto de unos 25 puntos menos. Además, la satisfacción del asesoramiento individual fue muy alta en un $40 \%$, alta en un $50 \%$ y parcial en un $10 \%$. (Andaroon et al. 2018)

En el estudio cualitativo hecho por Larsson et al., las mujeres informaron que el asesoramiento dirigido por las matronas mejoraba su confianza en el parto, se sentían empoderadas y tenían una mayor sensación de calma y preparación, que afectó positivamente en la experiencia del parto. Se vio reforzada la confianza en sí mismas para 
un futuro parto y se describió el miedo al parto como reducido o manejable. Las mujeres describieron que lo que influía en su experiencia de parto era su sensación de control durante este que era resultado del asesoramiento. La mayoría de las mujeres dijeron que el asesoramiento y la experiencia de parto positivo contribuía a que hubiera una disminución del miedo. (Larsson et al., 2019). En cambio, Larsson et al., en su estudio hecho con un diseño observacional longitudinal, encontraron que, aunque las mujeres se mostraron satisfechas con el asesoramiento recibido, esta siguió persistiendo un año después del parto. Su experiencia de parto fue expresada como más negativa y fuer más frecuente que las mujeres del grupo de asesoramiento prefiriesen tener una cesárea electiva en caso de otro parto. Además, era más probable que no quisieran tener más hijos. Esto nos muestra que el asesoramiento no funcionó tal y como estaba previsto. Los autores dicen que el estudio se vio comprometido porque no se envió el último cuestionario a las mujeres que no habían contestado a los otros tres, esto puede haber afectado a los resultados, ya que pocas mujeres que recibieron asesoramiento lo contestaron. (Larsson et al., 2015)

\section{Mindfulness}

Hay dos estudios que hablan sobre el mindfulness para reducir el miedo al parto (Duncan et al., 2017; Pour-Edalati et al., 2019). Entre ellos se observan diferencias en cómo se lleva a cabo la intervención.

En un ensayo controlado aleatorizado hecho por Duncan et al. se desarrolló un programa educacional llamado «Mind in Labor (MIL): Working with Pain in Childbirth», que enseña mindfulness para afrontar el dolor y el miedo al parto. Este programa incluía los objetivos de guiar a las participantes para entender el dolor del parto como sensaciones físicas desagradables que van y vienen, enseñar cómo desconectar el componente sensorial del dolor de sus componentes cognitivos y afectivos, el objetivo de disminuir el miedo y el sufrimiento relacionados con el dolor físico del parto, aprender a ser más conscientes de su propio cuerpo y de sus reacciones al dolor mediante la práctica consciente de hacer frente al dolor mediante una actividad de inducción del dolor con gel y desarrollar en las mujeres embarazadas y sus parejas estrategias personalizadas para proporcionarse soporte entre sí durante todo el proceso de parto (Duncan et al., 2017).

En un ensayo clínico hecho por Pour-Edalati et al., se aplicó el entrenamiento «Mindfulness-Based Stress Reduction» (reducción del estrés basada en el mindfulness). En las sesiones se enseñaba a hacer frente a obstáculos, la respiración basada en el 
mindfulness, estar en el momento presente. Se dieron algunas explicaciones sobre el estrés y su relación con el dolor, también se recalcó que los pensamientos no son hechos (PourEdalati et al., 2019)

Respecto a la efectividad de la intervención, los dos estudios están de acuerdo en su efectividad. Pour-Edalati et al. demostraron que es propicio para superar el miedo al parto. En consecuencia, también puede amplificar la tasa de lactancia y disminuir las cesáreas. Igualmente, Duncan et al. encontraron que la eficacia en el parto se incrementó en unos 4,7 puntos en el grupo que había seguido el tratamiento habitual y 78,2 puntos en el grupo de mindfulness.

\section{Educación prenatal}

Hay cuatro estudios en los que se habla sobre la educación prenatal. En todos ellos en el programa educativo se da información sobre el embarazo, los signos que indican el inicio del parto y cómo sería la sala de partos (Uçar y Golbasi, 2019; Haapio et al., 2017; Kizilirmak y Başer, 2016; Karabulut et al., 2016).

Además, en el programa educativo de un estudio hecho por Karabulut et al. se hacía una pequeña introducción sobre la anatomía y fisiología de hombres y mujeres y sobre los cambios fisiológicos, psicológicos, de alimentación, de ejercicio y de sexualidad durante el embarazo. También se explicaban signos de complicaciones durante el embarazo. Se hacía un plan de parto y se preparaba a la mujer para el parto enseñándole técnicas de respiración. Se explicaron las intervenciones que se le harían al recién nacido al nacer. Finalmente, se hizo un plan de familia y del periodo posparto en el que se promovía una buena autoestima en la mujer, que adquiriera el rol materno, y en el que se hablaba sobre las ventajas y desventajas de la lactancia materna y artificial (Karabulut et al., 2016).

En el programa de un estudio experimental hecho por Uçar y Golbasi también se enseñaron técnicas de respiración para hacer frente a las contracciones uterinas, al miedo al parto y para crear una percepción positiva de este (2019). En otro estudio experimental hecho por Kizilirmak y Baser també se explicó lo que es una episiotomía y también se compartieron experiencias de una mujer que dió a luz con éxito y positividad (2016). En un estudio elaborado por Haapio et al., el cual se incluye en la revisión sistemática hecha por Stoll et al., también se mostraron las diferentes formas de aliviar el dolor en el parto 
y la posición e instrumentos utilizados para el parto (Haapio et al., 2017; Stoll et al., 2018).

En cuanto a la efectividad de esta intervención, Karabulut et al. encontraron que la educación prenatal era efectiva en reducir el miedo al parto porque se vio que este había disminuido en el grupo que la había recibido (Karabulut et al., 2016).

En el estudio de Haapio et al. se encontró que los del grupo de intervención tenían menos miedo moderado y severo al parto que los del grupo control (80 \% vs. 85 \%). El miedo severo fue especialmente menor en el grupo de intervención que en el control. Concluye diciendo que la educación basada en la interacción tendría que ser la primera opción para ayudar a las mujeres a afrontar un parto (Haapio et al., 2017)

En los dos estudios experimentales hechos uno por Kizilirmak y Baser (2016), y el otro por Uçar y Golbasi (2019), se encontró que la educación reducía el miedo al parto. En los dos se utilizó el cuestionario W-DEQ-A, que determinaba el miedo al parto. En el primero la puntuación había disminuido 15 puntos en el grupo de intervención después de la educación. Por tanto, la educación reducía el miedo al parto y, además, también proporcionaba percepciones positivas del parto (Kizilirmak y Başer, 2016). En el segundo estudio la puntuación se redujo 24,5 puntos en el grupo de intervención después del programa educativo. Se concluyó que el programa educativo estaba asociado con menor dolor en el trabajo de parto, con una disminución de la duración de la segunda parte del parto y con ayuda para afrontar y reducir el miedo al parto (Uçar y Golbasi, 2019).

Por último, en una revisión sistemática y metaanálisis de ensayos clínicos se llegó a la conclusión de que la educación prenatal reducía el miedo al parto de forma significativa (Moghaddam Hosseini, Nazarzadeh y Jahanfar, 2018)

\section{Role play}

Solo hay un estudio que hable sobre la intervención mediante el uso de role play. Se trata de un estudio elaborado por Navaee y Abedian en Irán (2015).

La intervención consistía en un grupo de role play en el que se hizo una sesión que hablaba sobre las ventajas y desventajas de un parto natural y de una cesárea. Después se interpretaron tres escenarios. En el primer escenario, una de las participantes hizo el papel de una mujer que acudía a la consulta de la matrona para escoger el tipo de parto. La matrona le explicó los dos tipos de parto. Seguidamente, la mujer le expresó sus preocupaciones. Después de haber escogido el tipo de parto, las participantes discutieron 
la decisión de la embarazada. El segundo escenario era de una mujer que había tenido un parto natural y explicaba los beneficios y las complicaciones que le habían surgido. En el tercer escenario uno de los investigadores defendía la cesárea y el otro el parto vaginal. Al finalizar los tres escenarios, se pidió a las mujeres que hablaran de las experiencias de sus amigos/familiares en los dos tipos de partos. Los resultados de este mostraron que el role play era efectivo en la reducción del miedo al parto y en el aumento de partos naturales (Navaee y Abedian, 2015).

\section{Terapia con arte}

Solamente en uno de los estudios, elaborado por Wahlbeck Kvist y Landgren, se habla sobre la terapia con arte (2018). Cada sesión comenzaba con diez minutos de relajación. En cada sesión había un tema para dibujar como «pintar un árbol», «pintar un niño» o «pintar tu cuerpo». Otros temas como «ansiedad» y «control» sirvieron para dar a las mujeres la oportunidad de expresar sus sentimientos. En sesiones posteriores se tocaron temas como «hacia dónde voy?», «qué me está obstaculizando?» y «cómo puedo conseguir esto?», que sirvieron para crear una imagen mental de los objetivos que querían alcanzar. Durante las sesiones, se hicieron reflexiones de las imágenes con las participantes. En la sesión final se ilustró todo el proceso colgando todas las imágenes en el orden en el que fueron hechos para dar a la mujer la oportunidad final de reflexionar sobre su proceso terapéutico.

Las participantes de este dijeron que la pintura las había ayudado a descubrir sentimientos no percibidos antes. Después de la terapia, el miedo disminuyó y se sintieron más fuertes, tranquilas y seguras de sí mismas. Las mujeres describieron que el miedo se había depositado en las imágenes (Wahlbeck, Kvist y Landgren 2018).

\section{Psicoeducación}

En un estudio elaborado por Fenwick et al., se evaluaron los conocimientos, habilidades y confianza de las matronas para proporcionar asesoramiento psicoeducativo (2018).

Los resultados de este estudio demostraron que las matronas se beneficiaron del entrenamiento, que mejoró su confianza para ofrecer asesoramiento en psicoeducación a mujeres con niveles altos de miedo al parto. También expresaron que escuchaban mucho mejor y utilizaban los silencios de forma más adecuada. Casi la mitad de las participantes en el estudio afirmaban que no habían recibido nunca educación en esta área. 
Un $76 \%$ de las matronas dijeron que les faltaría tiempo para poder integrar el asesoramiento psicoeducativo en su práctica. Un 65 \% dijeron que una barrera también era la falta de continuidad asistencial con la misma matrona. En el entrenamiento se enseñaba que se tiene que mostrar amabilidad y hacer preguntas abiertas sobre la vida de la mujer y sus sentimientos delante del parto. Es importante escuchar y aceptar la perspectiva y opinión de la mujer. Se tiene que trabajar la perspectiva que tenga del parto y de los servicios de maternidad. Apoyar la expresión de sentimientos. Se han de conectar las emociones y creencias que tiene sobre el parto con alguna otra experiencia de parto que tenga la mujer e intentar que entienda de dónde le viene este miedo. No se tienen que defender o justificar cuidados que haya recibido anteriormente. Si es posible, cabe revisar el parto anterior y preguntarle si alguna cosa se tendría que haber hecho diferente, promover expectativas positivas, explicarle que el parto es un proceso natural pero significante. Se afirmó que la psicoeducación hecha por matronas es beneficiosa para las mujeres que tienen miedo al parto (Fenwick et al., 2018).

En una revisión sistemática hecha por Striebich et al., también se encontró que las sesiones de psicoeducación eran efectivas en la reducción del miedo al parto (2018).

\section{Preparación para el parto con acompañante (companion-integrated childbirth preparation)}

En una revisión sistemática Cochrane, en uno de los estudios incluidos, se afirma que sería bueno introducir a les parejas en la intervención, ya que la prevalencia de miedo al parto de estas es similar a la de las mujeres, de un 13 \% (O’connell et al., 2019). Hay un estudio de Munkhondyaet al. en el que se habla sobre la companion-integrated childbirth preparation (C-ICP), que es una intervención que educa y da soporte a mujeres primíparas y de sus acompañantes hacia el final del embarazo. Cada sesión de C-ICP duró de 1 h a 20 minutos aproximadamente. En estas se daba información sobre lo que se necesita para que haya un buen parto y los signos de peligro. También se explicaron los signos que indican el comienzo del trabajo de parto, cómo reducir de forma efectiva el dolor con técnicas de respiración y relajación, con masaje en la espalda y orinando a menudo cada $2 \mathrm{~h}$. Además se enseñó a empujar de forma efectiva durante el trabajo de parto. Más adelante, se describió lo que tiene que hacer la mujer cuando comienza el trabajo de parto y también lo que se espera que haga su acompañante, que es no dar medicación, darle soporte, tranquilizarla en la medida de lo posible y asegurarse de que recibe atención a tiempo. En el grupo de intervención, hubo una reducción del miedo al 
parto, un aumento de la autoeficacia en el parto y también del soporte recibido por el acompañante en comparación con el grupo control (Munkhondya et al., 2020).

Limitaciones del trabajo: Han faltado estudios hechos en España sobre las intervenciones que hacen las matronas para reducir el miedo al parto. Una gran parte de los estudios pertenecen a países nórdicos. Por este motivo, no tenemos evidencia de que los resultados se puedan aplicar en nuestro contexto geográfico.

\section{CONCLUSIONES}

Podemos afirmar que hay una gran variedad de intervenciones para el manejo del miedo al parto en mujeres embarazadas. Las intervenciones más usadas han estado: el asesoramiento (counselling), el mindfulness, la educación prenatal, el role play, la terapia con arte, la psicoeducación y la preparación para el parto con acompañante (companionintegrated childbirth preparation). Respecto al mejor modelo asistencial para la reducción del miedo al parto los estudios concluyen que es la continuidad asistencial.

En todas las intervenciones estudiadas el papel de la enfermera especialista en atención obstétrica y ginecológica (matrona) es fundamental. Por este motivo, hay que poner énfasis en la formación en estas técnicas durante los estudios de matrona, así como en la capacitación de las enfermeras y matronas para detectar aquellas mujeres que presentan miedo al parto.

En cuanto al asesoramiento (counselling) se ha visto que es efectivo para reducir el miedo al parto. Se ha encontrado que no hay un consenso con las actividades que se llevaban acabo en esta intervención. Sería muy útil una guía desarrollada para que todas las matronas siguieran los mismos pasos. El mejor modelo asistencial para reducir el miedo al parto es la continuidad asistencial de las matronas. Por eso, se tendría que trabajar para ofrecer este modelo a todas las mujeres embarazadas y también concienciar a las matronas de su importancia.

Por último, sería interesante investigar más sobre la eficacia de las intervenciones a largo plazo, ya que en los estudios analizados esta información no constaba, así como profundizar en los diferentes modelos de relación asistencial. Del mismo modo, también sería importante realizar más estudios en nuestro entorno geográfico y cultural en relación con la detección y abordaje del miedo al parto. 


\section{BIBLIOGRAFÍA}

ANDAROON, Nafise. The effect of individual counseling program by a midwife on fear of childbirth in primiparous women. En: Journal of education and health promotion. 2018, vol. 6, pp. 1-6.

BADAOUI, A.; KASSM, S.A.; NAJA, W. Fear and Anxiety Disorders Related to Childbirth: Epidemiological and Therapeutic Issues. En: Current Psychiatry Reports. 2019, vol. 21, núm. 4.

Cos, D. Association between fear of childbirth and maternal acceptance of pregnancy. En: International Nursing Review. 2017, vol. 64, núm. 4, pp. 576-583.

DEMŠAR, K., et al. Tokophobia (fear of childbirth): prevalence and risk factors. En: Journal of Perinatal Medicine. 2018, vol. 46, núm. 2, pp. 151-154.

DunCAN, L. G., et al. Benefits of preparing for childbirth with mindfulness training: A randomized controlled trial with active comparison. En: BMC Pregnancy and Childbirth. 2017, vol. 17, núm. 1, pp. 1-12.

EAD, S. I. N., et al. Worldwide prevalence of tocophobia in pregnant women: systematic review and meta-analysis. En: Acta obstetricia et gynecologica Scandinavica. 2017, vol. 96, pp. 907-920.

FENWICK, J., et al. Improving psychoeducation for women fearful of childbirth: Evaluation of a research translation project. En: Women and Birth. 2018, vol. 31, núm. 1, pp. 1-9.

HAAPIO, S., et al. Effects of extended childbirth education by midwives on the childbirth fear of first-time mothers: an RCT. En: Scandinavian Journal of Caring Sciences. 2017, vol. 31, núm. 2, pp. 293-301.

Hildingsson, I., et al. Caseload midwifery for women with fear of birth is a feasible option. En: Sexual and Reproductive Healthcare. 2018, vol. 16, pp. 50-55.

HILDINGSSON, I., KARLSTRÖM, A. et al. Women with fear of childbirth might benefit from having a known midwife during labour. En: Women and Birth. 2019, vol. 32, núm. 1, pp. 58-63.

Hildingsson, I.; Rubertsson, C., et al. A known midwife can make a difference for women with fear of childbirth- birth outcome and women's experiences of intrapartum care. Sexual and En: Reproductive Healthcare. 2019, vol. 21, pp. 33-38.

Karabulut, O., et al. Does antenatal education reduce fear of childbirth? En: International Nursing Review. 2016, vol. 63, núm. 1, pp. 60-67.

KIZILIRMAK, A.; BAȘER, M. The effect of education given to primigravida women on fear of childbirth. En: Applied Nursing Research. 2016, vol. 29, pp. 19-24.

LARSSON, B., et al. Women's experience of midwife-led counselling and its influence on childbirth fear: A qualitative study. En: Women and Birth. 2019, vol. 32, núm. 1, pp. 88-94. 
LARsson, B., et al. The effects of counseling on fear of childbirth. En: Acta Obstetricia et Gynecologica Scandinavica. 2015, vol. 94, núm. 6, pp. 629-636.

LARSSON, B., et al. Counseling for childbirth fear-a national survey. En: Sexual and Reproductive Healthcare. 2016, vol. 8, pp. 82-87.

LOWE, N. K. Self-efficacy for labor and childbirth fears in nulliparous pregnant women. En: Journal of Psychosomatic Obstetrics and Gynecology. 2000, vol. 21, núm. 4, pp. 219-224.

Moghaddam Hosseini, V.; NAZARZADEH, M.; JAHANFAR, S. Interventions for reducing fear of childbirth: A systematic review and meta-analysis of clinical trials. En: Women and Birth. 2018, vol. 31, núm. 4, pp. 254-262.

MunKHONDYA, B. M. J., et al. Efficacy of companion-integrated childbirth preparation for childbirth fear, self-efficacy, and maternal support in primigravid women in Malawi. En: BMC Pregnancy and Childbirth. 2020, vol. 20, núm. 1, pp. 1-12.

NAVAeE, M.; ABEDiAn, Z. Effect of role play education on primiparous women's fear of natural delivery and their decision on the mode of delivery. En: Iranian journal of nursing and midwifery research. 2015, vol. 20, núm. 1, pp. 40-6.

NiLSson, C., et al. Definitions, measurements and prevalence of fear of childbirth: a systematic review. En: BMC pregnancy and education. 2018, vol. 18, núm. 1, pp. 116.

O’CONNELl, M. A., et al. Interventions for fear of childbirth (Tocophobia). En: Cochrane Database of Systematic Reviews. 2019, vol. 5.

ORgAnizAción Mundial De LA SALUd. Recomendaciones de la OMS sobre el Nacimiento. Curso de medicina naturista. Ginebra: OMS, 2003. Disponible en: $<$ www.unizar.es/med_naturista/Tratamientos/Recomendaciones de la OMS sobre el Nacimiento.pdf $>$.

Ortega-Cejas, C. M., et al. Miedo al parto: revisión bibliográfica de los instrumentos de medida. En: Matronas profesión. 2019, vol. 20, núm. 2, pp. 36-42.

OTLEY, H. Fear of childbirth: Understanding the causes, impact and treatment. En: British Journal of Midwifery. 2011, vol. 19, pp. 215-220.

Pour-Edalati, M., et al. Exploring the Effect of Mindfulness-Based Stress Reduction on Childbirth Fear Among Single-Child Mothers in the City of Kerman, Iran (2017): A Clinical Trial Study. En: Medical-Surgical Nursing Journal. 2019, vol. 7, núm. 4. SAisto, T.; HalmesmäKI, E. Fear of childbirth: A neglected dilemma. En: Acta Obstetricia et Gynecologica Scandinavica. 2003, vol. 82, núm. 3, pp. 201-208.

SMITH, V., et al. Antenatal and intrapartum interventions for reducing caesarean section, promoting vaginal birth, and reducing fear of childbirth: An overview of systematic reviews. En: PLoS ONE. 2019, vol. 14, núm. 10, pp. 1-18. 
STOLL, K., et al. 2018. A systematic review of nonpharmacological prenatal interventions for pregnancy-specific anxiety and fear of childbirth. En: Birth. 2018, vol. 45, núm. 1, pp. 7-18.

Striebich, S.; MAtTern, E.; AyerLe, G. M. Support for pregnant women identified with fear of childbirth (FOC)/tokophobia - A systematic review of approaches and interventions. En: Midwifery. 2018, vol. 61, pp. 97-115.

SYDSJÖ, G., et al. Effects of continuous midwifery labour support for women with severe fear of childbirth. En: BMC Pregnancy and Childbirth, vol. 15, núm. 1, pp. 1-6.

UÇAR, T.; GOLBASI, Z. Effect of an educational program based on cognitive behavioral techniques on fear of childbirth and the birth process. En: Journal of Psychosomatic Obstetrics and Gynecology. 2019, vol. 40, núm. 2, pp. 146-155.

WAHLBECK, H.; Kvist, L. J.; LANDGREN, K. Gaining hope and self-confidence-An interview study of women's experience of treatment by art therapy for severe fear of childbirth. En: Women and Birth. 2018, vol. 31, núm. 4, pp. 299-306.

Wulcan, A. C.; Nilsson, C. Midwives' counselling of women at specialised fear of childbirth clinics: A qualitative study. En: Sexual and Reproductive Healthcare. 2019, vol. 19, pp. 24-30. 